\title{
Binding interactions between suberin monomer components and pesticides
}

\author{
M.À. Olivella ${ }^{\text {a,* }}$, C. Bazzicalupi ${ }^{\text {b }}$, A. Bianchi ${ }^{\text {b }}$, J.C. del Río ${ }^{c}$, N. Fiol ${ }^{\text {a }}$, I. Villaescusa ${ }^{\text {a }}$ \\ a Department of Chemical Engineering, Escola Politècnica Superior, Universitat de Girona, Maria Aurèlia Capmany, 61, 17071 Girona, Spain \\ b Department of Chemistry “Ugo Schiff”, University of Florence, Via della Lastruccia, 3, 50019 Sesto Fiorentino, Italy \\ ' Instituto de Recursos Naturales y Agrobiología de Sevilla, Consejo Superior de Investigaciones Científicas, P.O. Box 1052, 41080 Seville, Spain
}

\section{H I G H L I G H T S}

- Suberin has low affinity to retain pesticides of aliphatic character.

- Suberin has a moderate affinity to adsorb isoproturon.

- Modeling calculations show that apolar portion of suberin interacts with isoproturon.

- Modeling calculations evidence Van der Waals interactions play the major role.

- Presence of glycerol provokes changes in isoproturon and methomyl interactions.

\section{A R T I C L E I N F O}

\section{Article history:}

Received 21 March 2015

Received in revised form 29 April 2015

Accepted 29 April 2015

Available online $\mathrm{xxxx}$

Editor: Kevin V Thomas

\section{Keywords:}

Suberin

Isoproturon

Methomyl

Oxamyl

Molecular modeling

Van der Waals

Glycerol

\begin{abstract}
A B S T R A C T
Understanding the role of biomacromolecules and their interactions with pollutants is a key for elucidating the sorption mechanisms and making an accurate assessment of the environmental fate of pollutants. The knowledge of the sorption properties of the different constituents of these biomacromolecules may furnish a significant contribution to this purpose. Suberin is a very abundant biopolymer in higher plants. In this study, suberin monomers isolated from cork were analyzed by thermally-assisted methylation with tetramethylammonium hydroxide (TMAH) in a pyrolysis unit coupled to gas chromatography-mass spectrometry (GC/MS). The isolated monomer mixture was used to study the sorption of three pesticides (isoproturon, methomyl and oxamyl). The modes of pesticide-sorbent interactions were analyzed by means of two modeling calculations, the first one representing only the mixture of suberin monomers used in the sorption study, and the second one including glycerol to the mixture of suberin monomers, as a building block of the suberin molecule. The results indicated that the highest sorption capacity exhibited by the sorbent was for isoproturon (33\%) being methomyl and oxamyl sorbed by the main suberin components to a lesser extent ( $3 \%$ and $<1 \%$, respectively). In addition to van der Waals interactions with the apolar region of sorbent and isoproturon, modeling calculations evidenced the formation of a hydrogen bond between the isoproturon $\mathrm{NH}$ group and a carboxylic oxygen atom of a suberin monomer. In the case of methomyl and oxamyl only weak van der Waals interactions stabilize the pesticide-sorbent adducts. The presence of glycerol in the model provoked significant changes in the interactions with isoproturon and methomyl.
\end{abstract}

@ 2015 Published by Elsevier B.V.

\section{Introduction}

Biopolymers, including cellulose, hemicelluloses, lignin and suberin, which are the main components of the plants, are ubiquitous in the environment. While the monomeric composition of suberin is quite well known there is some controversy about the delimitation of the term suberin. Some authors argue that the term suberin should be

\footnotetext{
* Corresponding author.

E-mail address: angels.olivella@udg.edu (M.À. Olivella).
}

mainly restricted to aliphatic macromolecule (Graça and Pereira, 2000a). Concurrently, others refer to the aliphatic and aromatic character of suberin (Bernards, 2002). The role of suberin is to form a protective barrier between the plant and its environment (Bernards, 2002). The outer bark of higher plants and tuber periderms constitute the major sources of suberin in nature (Gandini et al., 2006). Suberin content and composition in outer barks is quite variable, depending of the wood species and of the isolation method used (Fengel and Wegener, 1984; Lopes et al., 2001). Suberin is particularly abundant in Quercus suber L. cork (30-50\%), a natural, renewable and biodegradable raw material (Jové et al., 2011). 
The environmental fate of toxic organic pollutants such as pesticides and PAHs is strongly influenced by the sorption process. Because of this, understanding the role of the biopolymers on the sorption of these pollutants is essential for the accurate assessment of the fate of pollutants in the environment. Moreover, in order to develop sustainable technologies based on natural sorbents for soil and water remediation, exploration of the capability of these biopolymers to retain or immobilize pollutants is essential.

Raw cork biosorption features towards organic pollutants have been recently investigated (Crespo-Alonso et al., 2013; Domingues et al., 2005, 2007; Nurchi et al., 2014; Olivella et al., 2011a, 2011b). Nevertheless, studies regarding the role of suberin in sorption processes are still scarce. Moreover, the investigation of the role of this biopolymer and the interactions involved is incomplete and the results controversial.

To the best of our knowledge, only Chen and Schnoor (2009) reported the role of suberin, suberan, and hemicelluloses in phenanthrene sorption by root tissue fractions. This study concluded that suberin was the major sorption medium for polycyclic aromatic hydrocarbons (PAHs). More recent studies have reported that suberin from raw cork does not play significant influence on hydrophobic organic pollutants sorption (Olivella et al., 2013).

Hence, this study gives some insights for a better understanding of the role of suberin in the sorption of some organic pesticides. For this purpose, suberin was first isolated from cork by alkaline hydrolysis and then chemically characterized by thermally-assisted methylation with tetramethylammonium hydroxide (TMAH) performed in a pyrolysis unit coupled to gas chromatography-mass spectrometry (GC/MS). The so obtained bundles of isolated suberin monomers were then used to sorb three pesticides of different chemical characteristics (i.e., isoproturon, methomyl and oxamyl). Based on the major suberin monomers identified, the interactions involved between suberin and pesticides were analyzed by molecular modeling.

\section{Experimental part}

\subsection{Sorbents and sorbates}

Granulated raw cork of $0.5-0.7 \mathrm{~mm}$ particle size was provided by a Catalonian cork industry. Pretreatment of raw cork to obtain the granulated form has been described elsewhere (Jové et al., 2011). Cork extractives were removed by successive Soxhlet extractions with dichloromethane $(6 \mathrm{~h})$, ethanol $(8 \mathrm{~h})$ and hot water $(20 \mathrm{~h})$ (Jové et al., 2011). The characteristics of the pesticides selected for this study are summarized in Table S1. All organic solvents (Romil, Cambridge) used were Super Purity grade. Standards of pesticides were purchased from Sigma-Aldrich (Madrid, Spain). All selected pesticides are non-ionic: isoproturon $\left(\mathrm{C}_{12} \mathrm{H}_{18} \mathrm{~N}_{2} \mathrm{O}, \log \mathrm{K}_{\mathrm{ow}}=2.25\right)$ with a moderate hydrophobicity; methomyl $\left(\mathrm{C}_{5} \mathrm{H}_{10} \mathrm{~N}_{2} \mathrm{O}_{2} \mathrm{~S}, \log \mathrm{K}_{\text {ow }}=0.60\right)$ and oxamyl $\left(\mathrm{C}_{7} \mathrm{H}_{13} \mathrm{~N}_{3} \mathrm{O}_{3} \mathrm{~S}\right.$, $\left.\log \mathrm{K}_{\mathrm{ow}}=-0.47\right)$ with hydrophilic character. Deionized water (Millipore Direct Q4 Water Purification system) was used for pesticide standard solution preparation and dilutions.

\subsection{Suberin depolymerization}

The extractive-free cork sample was submitted to alkaline depolymerization. Alkaline hydrolysis was carried out using a $0.5 \mathrm{M} \mathrm{KOH}$ in ethanol/water $(9: 1, \mathrm{v} / \mathrm{v})$ solution at $70{ }^{\circ} \mathrm{C}$ for $1.5 \mathrm{~h}$ (Pinto et al., 2009). The mixture of hydrolyzed suberin monomers was cooled to room temperature and acidified with dilute sulfuric acid to a $\mathrm{pH}$ of around 3-3.5, and then extracted three times with methyl $t$-butyl ether (MTBE). The solvent was then removed in a rotary evaporator and the residue weighed. This procedure yields suberin components like free acids, and preserves epoxide-containing structures (Ekman and Eckerman, 1985). Although most suberin monomer studies used alkaline methanolysis, in this study it may not be applied in terms of sorption because suberin structure is changed: acids are converted to methyl esters while epoxy-containing structures are largely converted to the corresponding methoxyhydrin structures.

\subsection{Analysis of suberin monomers by thermally-assisted methylation in the presence of tetramethylammonium hydroxide (TMAH)}

Thermally-assisted methylation was performed with approximately $1.0 \mathrm{mg}$ of suberin isolated in powdered form, mixed with approximately $5 \mu \mathrm{L}$ TMAH (25\% w/v in methanol), in a EGA/PY-3030D micro-furnace pyrolyzer (Frontier Laboratories Ltd.) connected to an Agilent 7820A gas chromatograph equipped with a DB-1701 (Agilent J\&W) fusedsilica capillary column ( $60 \mathrm{~m} \times 0.25 \mathrm{~mm}$ i.d., $0.25 \mu \mathrm{m}$ film thickness) and an Agilent 5975 mass selective detector ( $\mathrm{EI}$ at $70 \mathrm{eV}$ ). The pyrolysis unit was heated at $500{ }^{\circ} \mathrm{C}$. The oven temperature was programmed from $45{ }^{\circ} \mathrm{C}$ ( $\left.4 \mathrm{~min}\right)$ to $280{ }^{\circ} \mathrm{C}(10 \mathrm{~min})$ at $4{ }^{\circ} \mathrm{C} \mathrm{min}^{-1}$. Helium was used as carrier gas $\left(1 \mathrm{~mL} \mathrm{~min}^{-1}\right)$. The injector and detector were set at $300{ }^{\circ} \mathrm{C}$. The compounds were identified by comparison of retention times and mass spectra with those from our own collection of authentic standards and by comparison with Wiley and NIST mass spectral libraries and with those reported in the literature. The sum peak areas were normalized to 100 and the results of two averages are presented.

\subsection{Sorption experiments}

Batch equilibrium experiments were conducted at room temperature $\left(20 \pm 2{ }^{\circ} \mathrm{C}\right)$ on a rotary shaker (rotator STR4, Stuart Scientific Bibby) at 40 r.p.m, using $25 \mathrm{~mL}$ glass tapered tubes. In all experiments, $0.1 \mathrm{~g}$ of the mixture of suberin monomers were put into contact with $15 \mathrm{~mL}$ of pesticides aqueous solutions for $56 \mathrm{~h}$. Pesticides initial concentration was $5.4 \mu \mathrm{M}$. After sorption, samples were filtered through a $0.45 \mu \mathrm{m}$ filter to separate the solid fraction from the solution. Quantitative determination of non-sorbed pesticide concentration in solution was accomplished by high-performance liquid chromatography (HPLC) (Agilent technologies, 20120) using a ZORBAX Eclipse XDBC18 column ( $4.6 \mathrm{~mm}$ ID $\times 150 \mathrm{~mm}$ length). Detection of pesticides was performed at $210 \mathrm{~nm}$. The solid obtained after filtration was dried at $70{ }^{\circ} \mathrm{C}$ until constant weight and kept in a desiccator until its use. Quantification of pesticides concentration was performed with the

\section{Table 1}

Composition (\%) of the products (as their methyl derivatives) released from suberin after pyrolysis in the presence of TMAH.

\begin{tabular}{llcc}
\hline Peak & & Ret time & Percentage \\
\hline 1 & Dodecanoic acid & 35.590 & 0.3 \\
2 & Nonanedioic acid & 38.486 & 0.7 \\
3 & 3,4-Dimethoxybenzaldehyde & 38.581 & 1.0 \\
4 & 3,4-Dimethoxybenzenecarboxylic acid & 40.818 & 0.8 \\
5 & Tetradecanoic acid & 41.236 & 0.5 \\
6 & 3,4-Dimethoxybenzeneacetic acid & 41.989 & 0.6 \\
7 & Pentadecanoic acid & 43.834 & 0.3 \\
8 & cis-ferulic acid & 46.050 & 0.8 \\
9 & Hexadecanoic acid & 46.303 & 2.5 \\
10 & trans-ferulic acid & 49.103 & 8.0 \\
11 & Octadecanoic acid & 50.922 & 3.6 \\
12 & Eicosanoic acid & 55.140 & 0.8 \\
13 & Hexadecanedioic acid & 55.293 & 3.5 \\
14 & 18-Hydroxy-octadec-9-enoic acid & 56.159 & 4.8 \\
15 & Octadec-9-enedioic acid & 58.951 & 12.5 \\
16 & Docosanoic acid & 59.068 & 3.5 \\
17 & Octadecanedioic acid & 59.213 & 2.0 \\
18 & 9,10-Epoxyoctadecanoic acid & 61.454 & 2.0 \\
19 & Tetracosanoic acid & 62.678 & 1.7 \\
20 & Eicosanedioic acid & 62.907 & 1.8 \\
21 & 22-Hydroxydocosanoic acid & 63.957 & 12.7 \\
22 & 9,10-Dihydroxyoctadecanedioic acid & 64.035 & 6.6 \\
23 & 9,10-Epoxyoctadecanedioic acid & 64.706 & 2.7 \\
24 & 9,10,18-Trihydroxyoctadecanoic acid & 66.722 & 12.8 \\
25 & Docosanedioic acid & 67.070 & 12.4 \\
26 & 24-Hydroxytetracosanoic acid & 68.387 & 1.3 \\
\hline
\end{tabular}




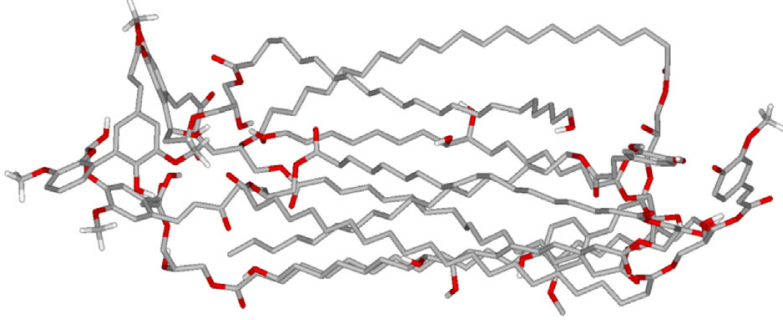

Fig. 1. The minimized suberin model including the main suberin monomers detected (i.e., octadec-9-enedioic acid; 22-hydroxydocosanoic acid; 9,10,18-trihydroxyoctadecanoic acid, docosanedioic acid and glycerol).

external calibration procedure $\left(R^{2} \geq 0.99, \mathrm{p}<0.001\right)$. Two blank experiments were carried out under the same experimental conditions as were the studied samples: the first blank was only Milli-Q water and the second blank was Milli-Q water with the suberin. All experiments were performed in duplicate.

Sorption results were calculated in terms of sorption percentages of the initial and final pesticide concentrations, respectively. A quite high pesticide concentration, corresponding to a suberin model/pesticide $1: 1$ ratio was used. The obtained model can be extrapolated to describe interactions between suberin and pesticides at concentration levels of $\mu \mathrm{g} \mathrm{L}^{-1}$ such as those found in aqueous compartments (de Gerónimo et al., 2014; Köck-Schulmeyer et al., 2013).

\subsection{Molecular modelings}

Molecular modeling calculations were carried out on the adducts formed by isoproturon, methomyl or oxamyl with two models of sorbent. One is a suberin model formed by the four most abundant acids found in our samples detected by the thermally-assisted methylation procedure (i.e., octadec-9-enedioic acid, 22-hydroxydocosanoic acid;, 9,10,18-trihydroxyoctadecanoic acid, docosanedioic acid), in 2:2:2:2 molar ratio, esterified with eight glycerol groups (in 6:2 R:S stereoisomeric ratio) bearing six ferulic acid residues (Table 1). As suggested by Bernards (2002) this model includes an aromatic moiety composed by three ferulic acids linked together by $\mathrm{C}-\mathrm{C}$ and ester bonds according to an aliphatic-aromatic suberin lamellae construction that, nevertheless, seems not to be always true for Quercus suber (Teixeira and Pereira, 2010). The model was subjected to repeated cycles of simulated heating followed by cooling and minimization ( $\mathrm{T}=400 \mathrm{~K}$, equilibration, run and cooling time $=5 \mathrm{ps}$, time step $=1.0 \mathrm{fs}$ ) to obtain the structure reported in Fig. 1 . The other model was generated from this structure upon removal of all the aromatic and the glycerol residues and successive protonation of the carboxylate groups. The resulting structure was then minimized. The latter model represents more closely the material used for the sorption experiments.

Starting conformations of the pesticide adducts with both sorbent models were obtained by manual docking and followed by minimization procedure. Potential energy surface of each system was explored by means of simulated annealing ( $\mathrm{T}=400 \mathrm{~K}$, equilibration, run and cooling time $=10 \mathrm{ps}$, time step $=1.0 \mathrm{fs}$ ), sampling 80 conformations for each studied adduct. All calculations were performed by using the AMBER3 forcefield, as implemented in the Hyperchem v.7.5 package (Hyperchem, 2002), with implicit treatment of the solvent effects ( $\varepsilon=4 \mathrm{R})$ and atomic charges calculated at semiempirical level by PM3 (Stewart, 1990).

\section{Results and discussion}

3.1. Suberin composition as observed by thermally-assisted methylation with TMAH

The chromatogram of the products released from the suberin sample after thermally-assisted methylation with TMAH (Table 1) is shown in Fig. 2. Although it is known that some differences may exist between thermally-assisted methylation with TMAH and methanolysis methods (i.e., the former may overestimate the relative abundance of ferulic acid and may underestimate the occurrence of epoxides) due to the complex heterogeneous structure of suberin and the differences in ether and ester labilities in alkaline medium, the thermally-assisted methylation with TMAH is still a powerful and relatively simple analytical approach to investigate the structure of the suberin polymer and to know the identities of their monomeric constituents (Bento et al., 2001; Olivella and del Río, 2011; del Río and Hatcher, 1998).

As shown in Table $1, C_{18}$ and $C_{22}$ monomers are predominant in similar relative abundances. The most abundant members of the $C_{18}$ family were octadec-9-enedioic acid (15) and 9,10,18-trihydroxyoctadecanoic acid (24). The former compound was found to be more abundant at the back anatomical part than in cork (i.e., anatomical part used for the production of cork stoppers) (Olivella and del Río, 2011). Among the trihydroxyacids, 9,10,18-trihydroxyoctadecanoic acid was reported to be the most abundant compound in cuticles from apple fruit and Agave Americana (del Río and Hatcher, 1998). The presence of this compound was also found in the early stages of fruit development

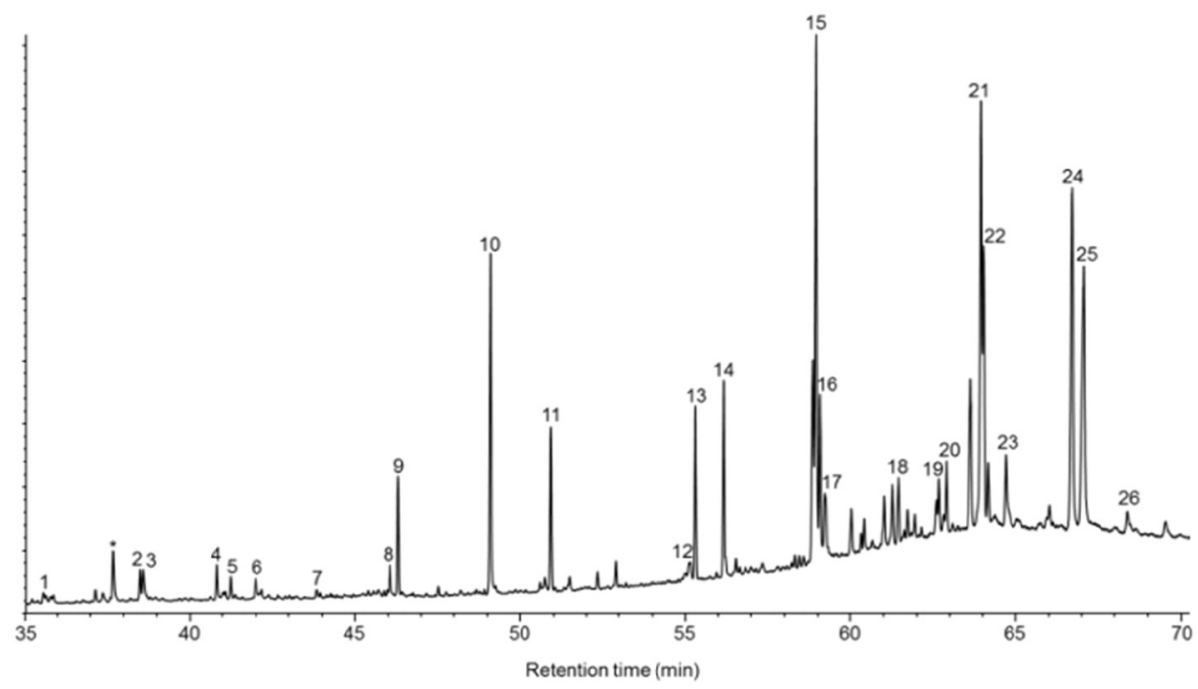

Fig. 2. Gas chromatograms of the products released from suberin after thermally-assisted methylation with TMAH. Peak numbers correspond to the compounds identified in Table 1. 

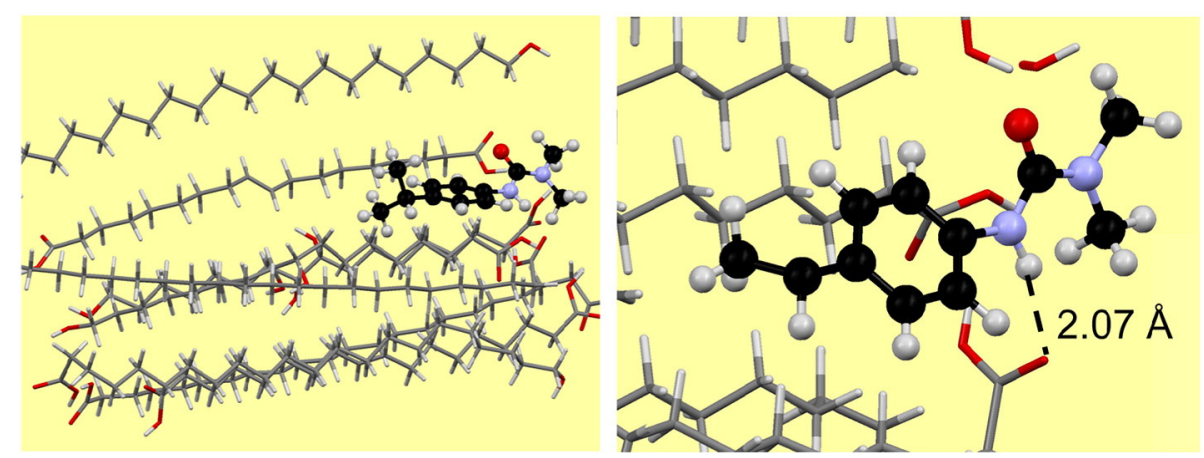

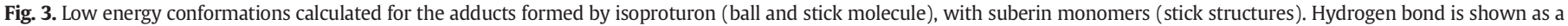
dashed black segment.

(Baker et al., 1982). However, it is necessary to mention that part of the content of 9,10,18-trihydroxyoctadecanoic acid may also arise from 9,10-epoxy-18-hydroxyoctadecanoic acid after cleavage of the epoxide ring during the thermally-assisted methylation with TMAH, as previously reported (del Río and Hatcher, 1998). Concerning the $C_{22}$ family, the most abundant compounds are 22-hydroxydocosanoic acid (21) and docosanedioic acid (25). These four above mentioned compounds (i.e., 15, 24, 21 and 25), representing 50\% of the total monomers content, were used for molecular modeling calculations.

Among the $\mathrm{C}_{16}$ monomers, hexadecanedioic acid (13) and hexadecanoic acid (9) were identified. Moreover, significant amounts of ferulic acid (10) were also identified. Nevertheless, it is important to emphasize that the cork suberin analyzed in this work contain predominantly $\mathrm{C}_{18}$ and $\mathrm{C}_{22}$ monomers.

Note that the main suberin monomers detected by thermallyassisted methylation with TMAH match those detected in cork without previous suberin isolation, namely octadec-9-enedioic acid (19.2\%), docosanedioic acid (15.9\%) and 9,10,18-trihydroxyoctadecanoic acid (9\%) (Olivella and del Río, 2011). So, it is expected that most of the suberin monomers considered for the model are fairly close to those really present in suberin structure.

Glycerol is a suberin component (Gandini et al., 2006). Small amounts of glycerol (usually in the range from 2 to 5.2\%) have been reported by different authors (Bento et al., 1998; Graça and Pereira, 1997; Parameswaran et al., 1981; Rosa and Pereira, 1994). In contrast, more recently other authors detected in the complete suberin extract by GC-FID analysis using the internal standard calibration procedure higher amounts of glycerol (up to $14 \%$ ) in $Q$. suber cork (Graça and Pereira, 2000b).

In this study, glycerol was not observed among the compounds released upon thermally-assisted methylation with TMAH of the suberin sample. In the mentioned chromatographic conditions, glycerol (as its trimethyl ether) could be expected to elute at a retention time of $14.1 \mathrm{~min}$, with characteristic fragments in the mass spectrum at $m / z 59$ (base peak), 89 and 102 (molecular ion), as it has been observed in other suberin samples (Bento et al., 2001). This absence is because polar suberin monomers such as glycerol, in principle, are not extracted with methyl $t$-butyl ether of non-polar character, remaining in the aqueous phase.

\subsection{Sorption studies of isoproturon, methomyl and oxamyl with suberin}

Regarding the results obtained in the sorption studies of the three pesticides using the main suberin monomers isolated from cork, the highest sorption yield was found for isoproturon (33\%). Methomyl (3\%) and oxamyl $(<1 \%)$ were poorly sorbed. These results put into evidence that the sorbent affinity for the pesticides is related to the hydrophobic character of the pesticide. That is the reason why the other two pesticides, that possess hydrophilic character, are poorly sorbed.

The result of isoproturon sorption onto the isolated suberin found in this work (33\%) is slightly lower than that from our previous study where the sorption of this pesticide was investigated onto raw cork (37\%) (Olivella et al., 2015). In this previous work, the interactions between aromatic pesticides and the cork matrix were attributed mainly to lignin moieties but also to suberin. Results of these studies suggest that both biopolymers, lignin and suberin, that possess aromatic and aliphatic character, respectively (Pereira, 2007), exhibit a good binding affinity for isoproturon.

An interpretation of the adsorption results was obtained at the molecular level by performing a molecular modeling of the interaction of pesticides with the more abundant suberin monomers. Since glycerol is a significant suberin component, we performed modeling calculations on the interaction with the three pesticides by using two models of sorbents: one representing the mixture of suberin monomers used in the sorption study, and one (hereafter indicated as suberin model) including glycerol and ferulic acid residues in addition to suberin monomers, which is more representative of the suberin composition.

The lowest energy conformers obtained for the interaction of the former model with each pesticide-sorbent system are shown in Figs. 3

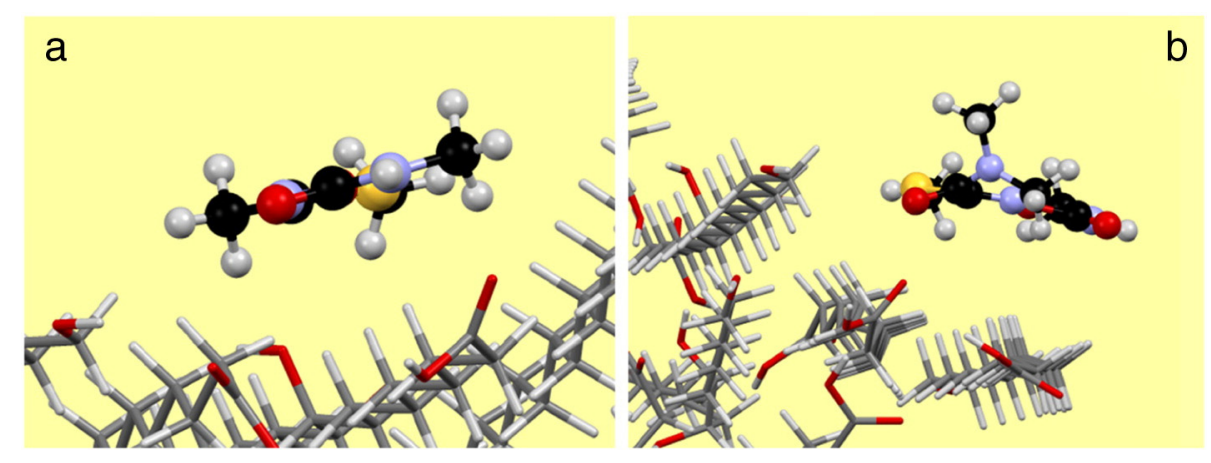

Fig. 4. Low energy conformations calculated for the adducts formed by (a) methomyl and (b) oxamyl (0) (ball and stick molecules), with suberin monomers (stick structures). 
and 4. First of all, it must be stressed here that the model used for the sorbent is an approximated model, representative of the four main components constituting the mixture of suberin monomers employed in the sorption experiments and of the random structure of this material. Also, the calculated structure of the pesticide adducts shown in Figs. 3 and 4 can be regarded as feasible interaction models. Within these
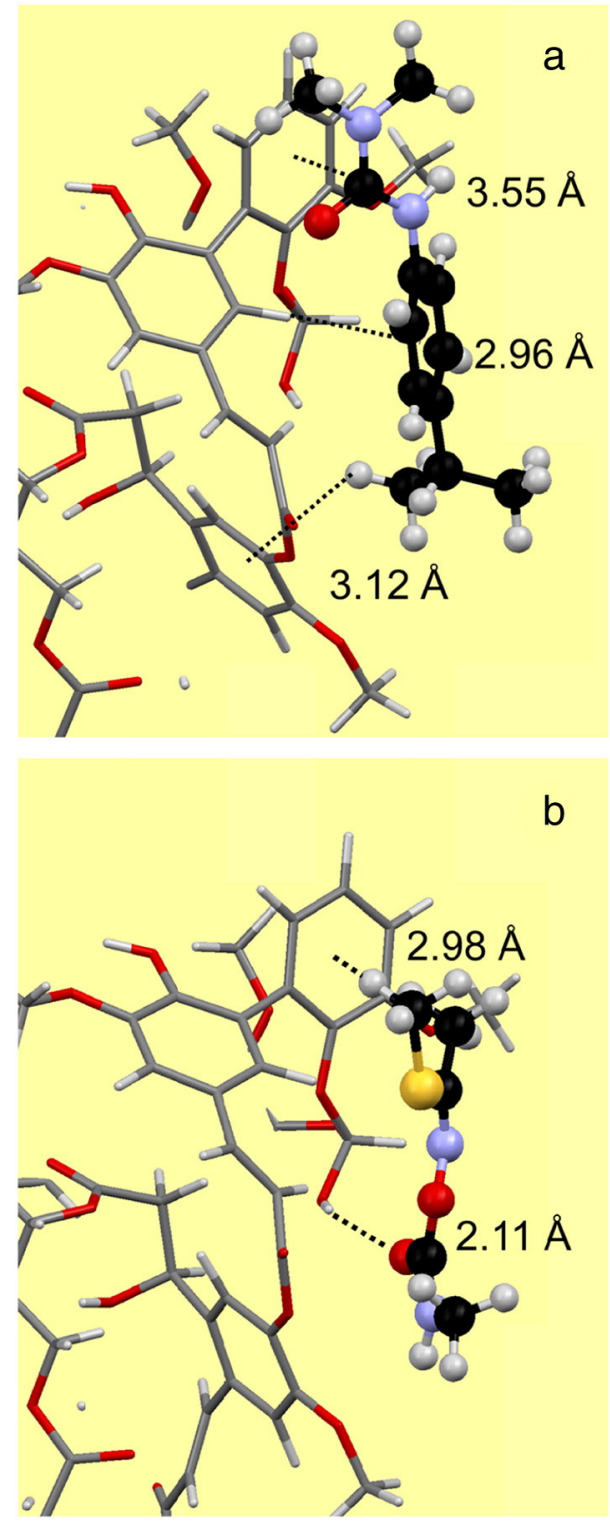

C

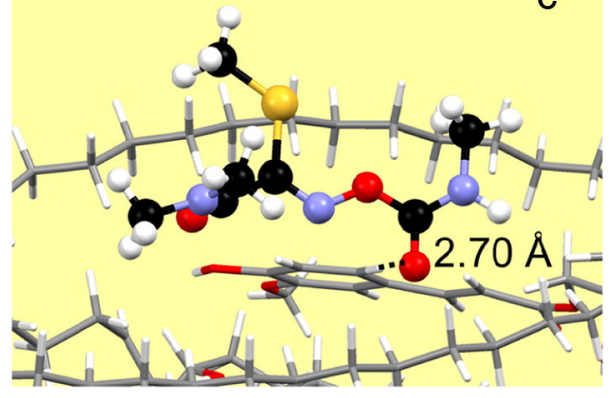

Fig. 5. Low energy conformations calculated for the adducts formed by (a) isoproturon, (b) methomyl and (c) oxamyl (ball and stick molecules) with the suberin model (stick structure) including glycerol and connected aromatic residues. Only the interacting sectors of the suberin model are shown. boundaries, the results obtained by modeling calculations allow to evidence interesting binding behaviors that make differences between the three substrates. As it can be seen in Fig. 3, isoproturon interacts with the terminal part of the suberin monomer lamellae, where its apolar portion forms van der Waals interactions, while its $\mathrm{NH}$ group forms a hydrogen bond with an oxygen atom of a sorbent carboxylic group ( $\mathrm{NH} \cdots \mathrm{OCOH}, 2.07 \AA$ A ). Conversely, both methomyl and oxamyl interact with the lamellae rims of suberin monomers, in the region of higher hydrophobic character where only van der Waals interactions are possible (Fig. 4). Nevertheless, the polar groups of methomyl are closer to the terminal polar groups of the sorbent than the polar groups of oxamyl. Accordingly, for this pesticide attractive dipole-dipole interactions that stabilize the methomyl-sorbent adduct are possible. Therefore considering that the energy of the weak forces involved in the formation of such pesticide-suberin adducts decreases in the order hydrogen bond $>>$ dipole-dipole $>$ van der Waals interactions and on the basis of the modeling results it can be concluded that the strength of these pesticide-sorbent interactions decreases in the order isoproturon $\gg$ methomyl $>$ oxamyl, in agreement with the sorption results. This trend seems to be a compromise between the hydrophobic character of the pesticide and the ability of amide groups to form hydrogen bonds. Indeed, isoproturon is more hydrophobic than methomyl and oxamyl but it is also more efficient in forming hydrogen bonds as generally are aromatic amides in comparison to aliphatic ones.

When the suberin model containing glycerol and aromatic residues (i.e., suberin monomers) is considered, rather different results are obtained by modeling calculations. The lowest energy structures calculated for the adducts of the three pesticides with this suberin model are shown in Fig. 5. As can be seen, the presence of glycerol and connected aromatic residues modify significantly the interaction mode of isoproturon (Fig. 5a) and methomyl (Fig. 5b), the two pesticides finding more favorable interactions with the aromatic region of the sorbent. In particular, isoproturon (Fig. 5a) forms three interactions with aromatic groups (one edge-to-face $\pi-\pi$ stacking, involving the isoproturon aromatic ring and an aromatic proton of the sorbent, one $\mathrm{CH}-\pi$ and one $\mathrm{CO}-\pi$ interactions), while methomyl (Fig. 5b) forms one $\mathrm{CH}-\pi$ and one $\mathrm{CO}-\pi$ interactions. Weaker van der Waals contacts contribute to further stabilize pesticide-sorbent adducts. On the contrary, oxamyl, constituted by a longer and more branched aliphatic chain shows a preference for the aliphatic section of the sorbent (Fig. 5c) where it interacts with the sorbent mainly through van der Waals contacts and by a C(aromatic) $\mathrm{H}-\mathrm{OC}$ hydrogen bond.

This kind of information is instrumental in understanding the contribution of suberin components to the sorption properties of suberin, to explore new applications of suberin and envisage the affinity of this biopolymer for organic pollutants. This affinity will be predicted on the basis of octanol/water partition coefficient and the chemical structure of the pollutant (i.e., ionic, molecular) without the need to determine sorption isotherms and calculate maximum sorption capacities which is the usual procedure in sorption studies.

The sorption data presented here show that in spite of their aliphatic character the suberin monomers studied in this work display their highest affinity for isoproturon, a pesticide of aromatic character, while a lower performance was observed for the sorption of methomyl and oxamyl, both exhibiting aliphatic character. Molecular modeling calculations indicated that the major interactions of isoproturon with suberin monomers are of van der Waals type and hydrogen bonding $(\mathrm{NH} \cdots \mathrm{OCOH})$, while only van der Waals interactions take place between suberin monomers and methomyl and oxamyl. If glycerol and connected aromatic residues are also included in the sorbent model (Fig. 5), modeling calculations show that the interactions of isoproturon and methomyl with the aromatic residues becomes of major importance while the aliphatic sorbent sector remains the principal location for oxamyl sorption.

Selected physicochemical properties and chemical structure of chemicals (Table S1). 


\section{Acknowledgments}

This research was funded by the Spanish Ministry of Science and Innovation as part of the projects CTM2010-15185 and CTM201237215-C02-01. Thanks to Margot Vansteenland for her technical assistance. The authors thank to AECORK for providing the cork samples.

\section{References}

Baker, E.A., Bukovac, M.J., Hunt, G.M., 1982. The Plant Cuticle. Academic Press, New York. Bento, M.F., Pereira, H., Cunha, M.A., Moutinho, A.M.C., Berg, K.J., Boon, J.J., 1998 Thermally assisted transmethylation GC-MS of suberin components in cork from Quercus suber L. Phytochem. Anal. 9, 75-87.

Bento, M.F., Pereira, H., Cunha, M.A., Moutinho, A.M.C., van den Berg, K.J., Boon, J.J., 2001. A study of variability of suberin composition in cork from Quercus suber L. using thermally assisted transmethylation GC-MS. J. Anal. Appl. Pyrolysis 57, 45-55.

Bernards, M.A., 2002. Demystifying suberin. Can. J. Bot. 80, 227-240.

Chen, B., Schnoor, J.L., 2009. Role of suberin, suberan and hemicelluloses in phenanthrene sorption by root tissue fractions of swichgrass (Panicum virgatum) seedlings. Environ. Sci. Technol. 43, 4130-4136.

Crespo-Alonso, M., Nurchi, V.M., Biesuz, R., Alberti, G., Spano, N., Pilo, M.I., Sanna, G., 2013. Biomass against emerging pollution in wastewater. Ability of cork for removal of ofloxacin from aqueous solutions at different pH. J. Environ. Chem. Eng. 1, 1199-1204.

de Gerónimo, E., Aparicio, V.C., Barbaro, S., Portocarrero, R., Jaime, S., Costa, Jose L., 2014. Presence of pesticides in surface water from four sub-basins in Argentina. Chemosphere 107, 423-431.

del Río, J.C., Hatcher, P.G., 1998. Analysis of aliphatic biopolymers using thermochemolysis with tetramethylammonium hydroxide (TMAH) and gas chromatography-mass spectrometry. Org. Geochem. 29, 1441-1451.

Domingues, V., Alves, A., Cabral, M., Delerue-Matos, C., 2005. Sorption of behaviour of bifenthrin on cork. J. Chromatogr. A 1069, 127-132.

Domingues, V., Priolo, G., Alves, A., Cabral, M., Delerue-Matos, C., 2007. Adsorption behaviour of $\alpha$-cypermethrin on cork and activated carbon. J. Environ. Sci. Health B 42, 649-654

Ekman, R., Eckerman, C., 1985. Aliphatic carboxylic acids from suberin in birch outer bark by hydrolysis, methanolysis, and alkali fusion. Pap. Puu 67 (4), 255-273.

Fengel, D., Wegener, G., 1984. Chemical composition and analysis of wood. In: de Gruyter (Ed.), Wood: Chemistry, ultrastructure, reactions. De Gruyter, Berlin-New York, pp. 55-59.

Gandini, A., Pascoal Neto, C., Silvestre, A.J.D., 2006. Suberin: a promising renewable resource for novel macromolecular materials. Prog. Polym. Sci. 31, 878-892.

Graça, J., Pereira, H., 1997. Cork suberin: a glyceryl based polyester. Holzforschung 51 225-234.
Graça, J., Pereira, H., 2000a. Suberin structure in potato periderm: glycerol, long chain monomers and glyceryl and feruloyl dimmers. J. Agric. Food Chem. 48, 5476-5483.

Graça, J., Pereira, H., 2000b. Methanolysis of bark suberins: analysis of glycerol and acid monomers. Phytochem. Anal. 11, 45-51.

Hyperchem release 7.5 for Windows MM System, 2002. Hypercube, Inc., Gainesville, FL

Jové, P., Olivella, M.À., Cano, L., 2011. Study of the variability in chemical composition of bark layers of cork from different production areas. Bioresources 6 (2), 1806-1815.

Köck-Schulmeyer, M., Villagrasa, M., López de Alda, M., Céspedes-Sánchez, R., Ventura, F. Barceló, D., 2013. Occurrence and behavior of pesticides in wastewater treatment plants and their environmental impact. Sci. Total Environ. 458-460 (1), 466-476.

Lopes, M.H., Barros, A.S., Pascoal Neto, C., Rutledge, D., Delgadillo, I., Gil, A.M., 2001. Variability of cork from Portuguese Quercus suber studied by solid-state ${ }^{13} \mathrm{C}-\mathrm{NMR}$ and FTIR spectroscopies. Biopolymers 62, 268-277.

Nurchi, V.M., Crespo-Alonso, M., Biesuz, R., Alberti, G., Pilo, M.I., Spano, N., Sanna, G., 2014 Sorption of chrysoidine by row cork and cork entrapped in calcium alginate beads. Arab. J. Chem. 7 (1), 133-138.

Olivella, M.À., del Río, J.C., 2011. Suberin composition from different bark layers of Quercus suber $\mathrm{L}$. by Py-GC/MS in the presence of TMAH. Bioresources 6 (4), 4936-4941.

Olivella, M.À., Jové, P., Oliveras, A., 2011a. The use of cork waste as a biosorbent for persistent organic pollutants - study of adsorption/desorption of polycyclic aromatic hydrocarbons. J. Environ. Sci. Health A 46, 824-832.

Olivella, M.À., Jové, P., Sen, A., Pereira, H., Villaescusa, I., Fiol, N., 2011b. Sorption performance of Quercus Cerris cork with polycyclic aromatic hydrocarbons and toxicity testing. Bioresources 6 (3), 3363-3375.

Olivella, M.À., Jové, P., Bianchi, A., Bazzicalupi, C., Cano, L., 2013. An integrated approach to understanding the sorption mechanism of phenanthrene by cork. Chemosphere 90, 1939-1944.

Olivella, M.À., Bazzicalupi, C., Bianchi, A., Fiol, N., Villaescusa, I., 2015. New insights into the interactions between cork chemical components and pesticides. The contribution of $\pi-\pi$ interactions, hydrogen bonding and hydrophobic effect. Chemosphere 119, $863-870$.

Parameswaran, N., Liese, W., Gunzerodt, H., 1981. Características do verde da cortiça de Quercus suber L. Cortiça 514, 179-184.

Pereira, H., 2007. The chemical composition of cork. In: Pereira, H. (Ed.), Cork: Biology Production and Uses. Elsevier, Amsterdam, pp. 55-101.

Pinto, P.C.R.O., Sousa, A.F Silvestre, A.J. Neto, P. G Gandini, A Eckerman, C Holmbom, B., 2009. Quercus suber and Betula pendula outer barks as renewable sources of oleochemicals: a comparative study. Ind. Crops Prod. 29, 126-132.

Rosa, M.E., Pereira, H., 1994. The effect of long term treatment at $100{ }^{\circ} \mathrm{C}-150^{\circ} \mathrm{C}$ on structure, chemical composition and compression behavior of cork. Holzforschung 48, 226-232.

Stewart, J.P.P., 1990. Special issue-Mopac-a semiempirical molecular-orbital program. J. Comput-Aided Mol. Des. 4, 1-105.

Teixeira, R.T., Pereira, H., 2010. Suberized cell walls of cork from cork oak differ from other species. Microsc. Microanal. 16, 569-575. 